\title{
IDENTIDAD PERSONAL Y ONTOLOGÍA DE LA PERSONA
}

\author{
José Tomás Alvarado Marambio* \\ doi:10.11144/Javeriana.uph33-66.ipop
}

\begin{abstract}
RESUMEN
Se argumenta aquí que es parte de nuestro concepto de 'persona' que las personas deben ser, por su naturaleza, aptas para 'endurar' en el tiempo. En ninguna concepción de las personas como entidades que 'perduran', con diferentes partes temporales para diferentes tiempos, o como secuencias de etapas que se encuentran entre sí en la relación de 'ser un superviviente de', es posible hacer inteligibles algunas de nuestras intuiciones normativas acerca de las personas. Se argumenta también que la teoría psicológica tradicional de la identidad personal es insostenible. La continuidad psicológica parece ser ni suficiente, ni necesaria para la identidad personal. Una concepción razonable de las personas parece ser o bien, una forma de 'animalismo' en donde las personas son organismos biológicos, o una teoría en la que las personas son sustancias primitivas, con condiciones de identidad también primitivas.
\end{abstract}

Palabras clave: identidad; ontología; persona; continuidad psicológica; entidad

* Pontificia Universidad Católica de Chile, Santiago de Chile, Chile.

Correo electrónico: jose.tomas.alvarado@gmail.com

Para citar este artículo: Alvarado Marambio, J.T. (2016). Identidad personal y ontología de la persona. Universitas Philosophica, 33(66), pp. 77-112. ISSN 0120-5323, ISSN en línea: 23462426, doi:10.11144/Javeriana.uph33-66.ipop 


\title{
PERSONAL IDENTITY AND ONTOLOGY OF PERSON
}

\author{
José Tomás Alvarado Marambio
}

\begin{abstract}
It is argued here that it is part of our concept of a 'person' that persons should be, by its nature, able to endure in time. In no conception of persons as 'perduring' entities with different temporal parts for different times, or as sequences of stages in the relation of 'being a survival of' between them, it is possible to make sense of some of our normative intuitions about persons. It is argued also that the traditional psychological theory of personal identity is untenable. Psychological continuity appears to be neither sufficient nor necessary for personal identity. A reasonable conception of persons seems to be either a form of 'animalism' where persons are biological organisms, or a theory in which persons are primitive substances, with primitive conditions of identity.

Key words: identity; ontology; person; psychological continuity; entity
\end{abstract}


HAY UNA EXTENSA TRADICIÓN FILOSÓFICA que ha pretendido analizar la identidad personal desde un punto de vista que podría denominarse, de manera general, como 'psicológico'. Esta tradición se remonta, por lo menos, a John Locke (1690, II, ch. 27). En este trabajo se pretende mostrar que todo el programa de investigación de las teorías psicológicas es un fracaso y que las únicas teorías razonables de la identidad personal -teorías no nihilistas- son el animalismo y las teorías en las que las personas son sustancias primitivas. Bajo supuestos normativos razonables, el animalismo obliga a respetar como personas a embriones, fetos y organismos humanos en estado vegetativo. Si uno quiere resistir estas consecuencias, parece que lo más razonable sería adoptar una concepción dualista. Por su parte, las teorías psicológicas se han presentado como recogiendo y refinando la concepción 'forense' de persona. Se va a sostener aquí, sin embargo, que guiar nuestras decisiones normativas de acuerdo con las teorías psicológicas sería un desastre.

La estructura de este trabajo será la siguiente: en la primera sección se va a explicar qué tipo de conexión sistemática general debe postularse entre las condiciones de identidad y la ontología de una persona. En la segunda sección se presentarán las restricciones normativas que el concepto de persona debe satisfacer o que, por lo menos, supondremos que debe satisfacer. En la tercera sección se mostrarán las razones por las que las teorías psicológicas deben ser rechazadas -en bloque- como alternativas razonables para explicar las condiciones de identidad de una persona. En la cuarta sección se considerarán las alternativas razonables que subsisten para explicar las condiciones de identidad de una persona: el animalismo y alguna concepción de las personas como sustancias primitivas.

\section{Condiciones de identidad}

LAS CONDICIONES DE IDENTIDAD de un objeto u otra entidad son aquellas condiciones necesarias y suficientes para que una entidad a -del tipo específico de entidad de que se trate- sea o no idéntica a una entidad b del mismo tipo específico. La forma general de las condiciones de identidad para los casos de un tipo $F$ es la siguiente: 
- Identidad: es necesario que, para todo $F \alpha$ y $\beta: \alpha=\beta$ si y solo si, $\alpha$ y $\beta$ están en la relación \#1.

Aquí los cuantificadores que tienen como rango las variables ' $\alpha$ ' y ' $\beta$ ' son irrestrictos. La relación de equivalencia '\#’ es aquello en que consiste la identidad de $\alpha$ y $\beta^{2}$. Las condiciones de identidad deben valer de manera necesaria y por eso los cuantificadores en este caso están precedidos por un operador modal de necesidad. En efecto, si dos entidades $\alpha$ y $\beta$ son idénticas, deben ser necesariamente idénticas ${ }^{3}$. Si es el caso que actualmente a es idéntico con b entonces en todos los mundos metafísicamente posibles $\alpha$ es idéntico con $\beta$. En el mundo actual, por hipótesis, la identidad de $\alpha$ y $\beta$ depende de que satisfagan la relación \#. La identidad de un objeto está fundada en su esencia, que es aquello que hace que el objeto sea el que es en cualquier mundo posible. Si $P$ es parte de la esencia de $x$, entonces lo mínimo que se exige es que sea necesario que, si $x$ existe, entonces es $P$. Si aquello de lo que depende la identidad de una entidad a es parte de su esencia, no puede ser que aquello en virtud de lo cual $\alpha$ es idéntico con $\beta$ deje de darse en algún mundo posible en que $\alpha$ y $\beta$ existan. No puede ser, entonces, que aquello en que consiste la identidad de algo sea variable en diferentes mundos posibles. Si las condiciones de identidad de $F$ están actualmente fijadas por la relación \#, necesariamente están fijadas por la relación \#.

Para considerar cómo funciona un principio de identidad de la forma antes expuesta, puede ayudar tener en cuenta el principio de extensionalidad para conjuntos. Dos conjuntos son el mismo conjunto si y solo si poseen exactamente los mismos elementos. Haciendo las sustituciones necesarias, resulta que:

1 De un modo más preciso: $[\square \forall \alpha \forall \beta \square((F \alpha \wedge F \beta) \rightarrow((\alpha=\beta) \leftrightarrow(\alpha \# \beta)))]$.

2 Una relación de equivalencia es una relación reflexiva, simétrica y transitiva. La identidad puede ser entendida como la más pequeña relación de equivalencia, pues para toda relación diádica reflexiva, simétrica y transitiva $R$ y cualesquiera objetos $x \mathrm{e} y$, vale que: $[(x=y) \rightarrow R x y]$. La relación que deben satisfacer las entidades que resulten idénticas debe ser una relación de equivalencia, si es que va a valer el bicondicional cuantificado en el principio Identidad.

3 Sea, por hipótesis, que $[x=y]$. Es obvio que $[\square(x=x)]$. Sin embargo, $[(x=y) \rightarrow(F x \rightarrow F y)]$ por la Ley de Leibniz. Si se sustituye aquí $F$ por $[\square(x=v)]$ resulta que $[(x=y) \rightarrow(\square(x=x) \rightarrow \square(x=y))]$. Por aplicación reiterada de modus ponens se sigue que $[\square(x=y)]$. Así, si $[x=y]$, entonces $[\square(x=y)]$. 
Conjuntos: es necesario que para conjuntos $x$ e $y: x=y$ si y solo si, para todo $z$, $z$ es un elemento de $x$ si y solo si $z$ es un elemento de $y^{4}$.

La relación de equivalencia en que consiste la identidad de dos conjuntos es la relación de tener los mismos elementos. Si hubiese un elemento de uno de los conjuntos que no fuese también elemento del otro, entonces no se satisfaría la relación de equivalencia y, por lo tanto, los conjuntos deberían ser diferentes.

Las condiciones de identidad de entidades del tipo $F$ no son lo mismo que los criterios que nos permitirían llegar a saber que dos entidades del tipo $F$ son o no idénticas, o que nos permitirían llegar a tener una creencia justificada de que dos entidades del tipo $F$ son o no idénticas. Las condiciones de identidad son aquello en que consiste ontológicamente algo de tipo $F$ o es aquello en que está fundada ontológicamente la identidad de algo de tipo $F$, sea que estas condiciones nos resulten manifiestas desde un punto de vista epistemológico o no. Las condiciones de identidad de un tipo de entidad, si es que no van a ser triviales, especifican en qué consisten los hechos acerca de la identidad o diferencia de las entidades de tipo $F$ en términos de la identidad y diferencia de entidades de otros tipos que deben considerarse ontológicamente más básicas. Por ejemplo, cuando se especifican las condiciones de identidad de un conjunto por la identidad de sus elementos, debe suponerse que hay hechos determinados acerca de la identidad o diferencia de tales elementos. $\mathrm{Si} z=v$ no está ontológicamente determinado, entonces tampoco puede estarlo el caso de que el conjunto $a=\{z, t\}$ es idéntico o diferente al conjunto $b=\{v, t\}$. Cualesquiera que sean las entidades en cuyos términos las condiciones de identidad de un $F$ vengan dadas, los $F$ serán ontológicamente dependientes de tales entidades. Si las condiciones de identidad de un conjunto vienen dadas por cuales sean sus elementos, entonces los conjuntos habrán de ser ontológicamente dependientes de tales elementos 5 .

4 De un modo más preciso: [ $\square \forall x \forall y \square((x$ es un conjunto $\wedge y$ es un conjunto $) \rightarrow((x=y) \leftrightarrow \forall z$ $((z \in x) \leftrightarrow(z \in y)))]$.

5 De un modo general, se puede caracterizar a la dependencia ontológica como aquella relación en que se encuentran dos entidades $\alpha$ y $\beta$, tal que está inscrito en la esencia de $\alpha$ la existencia de $\beta$. Así, si $\alpha$ depende de $\beta$, entonces $[K((\alpha$ existe) " $(\beta$ existe $))]$. La dependencia no puede analizarse, sin embargo, como una implicación estricta como esta, pues entonces resultaría que todo sería ontológicamente dependiente de entidades necesarias y que, por ejemplo, un objeto $a$ dependería de $\{a\}$. 
No puede suponerse que siempre puedan entregarse condiciones de identidad no triviales para un tipo de entidad $F$ en términos de entidades de otro tipo $G$. Si las condiciones de identidad de los conjuntos vienen dadas por las condiciones de identidad de sus elementos, no es necesario que luego existan condiciones de identidad no triviales de los elementos. Las condiciones de identidad de un tipo de ente siguen a las dependencias ontológicas de esas entidades en otras que han de ser ontológicamente más 'básicas' o 'prioritarias'. Así, parece razonable suponer que debe haber entidades 'primeras', independientes respecto de toda otra entidad. Las condiciones de identidad de las entidades 'primeras' no podrán entonces venir constituidas por nada. Son primitivas. El que no tengamos éxito en especificar condiciones de identidad con la forma del principio Identidad para algo no debe verse, entonces, como un motivo para considerarlo como 'sospechoso' ontológicamente. No toda identidad debe poder explicarse reductivamente o estar fundada en la identidad de otras cosas más básicas. Esto no puede valer, por de pronto, para las cosas más básicas. Para el tema que aquí interesa, resulta que no debe suponerse que es necesario que existan condiciones de identidad reductivas para las personas. En abstracto, nada impide que se las entienda como entidades ontológicamente básicas, no dependientes en nada ${ }^{6} \mathrm{y}$ con condiciones de identidad primitivas.

Las condiciones de identidad de un tipo de entidad deben regir, de un modo especial, la identidad modal y la identidad temporal de un objeto. Un 'mundo posible' debe entenderse como una forma en que podrían ser todas las cosas. Es una creencia generalmente aceptada que las cosas podrían ser diferentes de como son -al menos, las cosas o hechos contingentes. Esto es, es una creencia comúnmente aceptada que hay formas en que podrían ser las cosas diferentes de la forma en que son de hecho las cosas. Un 'mundo posible' es simplemente una de estas formas. Es una creencia generalmente aceptada, por lo tanto, que hay mundos posibles. Algo es necesario si existe, sin importar qué mundo posible sea actual. Algo es contingente si existe bajo el supuesto de que ciertos mundos posibles fuesen actuales, y no lo haría si es que otros mundos posibles lo fuesen. Los

6 De hecho, esto es lo que se ha sostenido tradicionalmente cuando se ha caracterizado a una sustancia como una entidad independiente, que por su naturaleza es por sí y no por otro. Las personas han sido concebidas como casos paradigmáticos de sustancia. 
hechos acerca de la identidad de $x$ entre diferentes mundos posibles son los hechos acerca de qué entidades en otros mundos son o no idénticos a $x$. Las condiciones de identidad de $x$ especifican, en lo modal, qué tipo de vicisitudes podrían o no acaecerle a $x$. Hay propiedades que $x$ posee en ciertos mundos posibles que no posee en otros. Hay otras propiedades que $x$ posee en todos los mundos posibles. Las primeras son accidentales a $x$; las segundas, esenciales a $x$.

Pero las condiciones de identidad de una entidad no solo tienen relevancia para la especificación de las vicisitudes que podrían -o no- acaecerle a esa entidad. Tienen también relevancia para la especificación de las vicisitudes que puede o no sufrir una entidad en el tiempo. De un modo general, persistir para una entidad $x$ entre los instantes de tiempo $t_{1}$ y $t_{2}$ es haber un $y$-en- $t_{2}$, tal que $x$-en- $t_{1}$ $=y$-en- $t_{2}$. Las condiciones de identidad determinan si una entidad persiste o no entre dos tiempos. Al menos, debe suponerse tal cosa si el tipo de entidad de que se trate es algo que persiste por endurar en el tiempo. Se dice que $x$ 'endura' entre los tiempos $t_{1}$ y $t_{2}$ si y solo si $x$-en- $t_{1}=x$-en- $t_{2}$. Hay tipos de entidades que no persisten en el tiempo de este modo. No lo hacen, por ejemplo, los eventos. La Segunda Guerra Mundial no dura entre 1939 y 1945 por ser la misma entidad en todos los instantes de tiempo de su duración, sino por tener partes temporales correspondientes a cada uno de esos instantes. Un partido de fútbol dura $90 \mathrm{mi}-$ nutos por tener dos partes numéricamente diferentes entre sí de 45 minutos cada una. Se dice de una entidad que persiste entre diferentes tiempos por poseer diferentes partes temporales para esos tiempos que 'perdura ${ }^{7}$. Actualmente hay muchos que sostienen que la persistencia de toda entidad en el tiempo solo es inteligible por perduración (Heller, 1990; Lewis, 1976, pp. 76-77; 1986, pp. 202-204; Noonan, 2003, pp. 196-231). Lo que usualmente consideramos un objeto persistiendo en el tiempo es aquí simplemente una suma o fusión

7 Se suele distinguir en la literatura una tercera forma de persistencia por 'exduración' (Haslanger, 2003, pp. 317-320). Un objeto $x$ 'exdura' entre los tiempos $t_{1}$ y $t_{2}$ si y solo si hay un $y$-en- $t_{2}$ que es una contrapartida de $x$-en- $t_{1}$. La noción de una 'contrapartida' ha sido desarrollada inicialmente en metafísica modal (Lewis, 1968). Una contrapartida de $x$ es una entidad suficientemente semejante a $x$ en los respectos que sean contextualmente relevantes. La contrapartida de $x$ es diferente numéricamente de $x$. 
mereológica ${ }^{8}$ de partes temporales correspondientes a cada uno de los tiempos de persistencia. Nuestra concepción de sentido común acerca de los objetos particulares, sin embargo, es típicamente la de entidades que persisten por endurar y no por perdurar. Las personas han sido entidades para las que típicamente se han buscado condiciones de enduración en el tiempo. Todo el problema tradicional de la 'identidad personal' ha sido, en efecto, un problema acerca de la enduración de las personas. Aquí se va a postular que algo que no endure en el tiempo -o que, por lo menos, no sea una entidad apta para endurar en el tiempo- no merece el nombre de "persona", tal como se explicará más adelante.

Las condiciones de identidad de cierto tipo de entidades imponen restricciones importantes para postular una concepción acerca de su naturaleza. No determinan completamente, sin embargo, cuál sea tal concepción. Por ejemplo, es determinante de la identidad de un conjunto la identidad de sus elementos. Una fusión mereológica de estos mismos elementos tendrá también su identidad determinada por la identidad de estos. Esto no es un motivo, sin embargo, para sostener que un conjunto es lo mismo que una fusión mereológica. Cuando se trata de la cuestión acerca de las condiciones de identidad de una persona sucede algo semejante. En términos generales, no puede suponerse que la respuesta a la pregunta acerca de qué son las personas sea automáticamente la respuesta para la pregunta acerca de cuáles sean las condiciones de identidad de una persona. Uno puede sostener, por ejemplo, que es determinante para la identidad de una persona la identidad de un organismo biológico, pero esto es compatible con sostener que las personas -al menos las personas humanas- son organismos biológicos, también lo es con sostener que las personas están constituidas por un único organismo biológico y, por último, con sostener que la persona es una sustancia con propiedades irreductibles de tipo mental y de tipo físico, de modo que una misma persona ha de estar correlacionada con un único organismo biológico, que

8 La fusión de los $F$ es aquel todo con el que algo se sobrelapa si y solo si se sobrelapa con un $F$. De un modo intuitivo, se puede pensar en la fusión de los $F$ s como aquel todo que tiene como partes solo a cosas que son $F$ y todo lo que es $F$ es parte de ese todo. Se dice que $x$ 'se sobrelapa con' $y$ si y solo si $x$ e $y$ tienen al menos una parte (impropia) en común. Aunque nuestra intuición ordinaria es que la parte de $z$ debe ser 'más pequeña' que $z$, una 'parte impropia' de $z$ puede ser idéntica a $z$. Todo es trivialmente parte impropia de sí mismo. 
resulta de la organización que efectúa la sustancia sobre ciertos materiales?. Solo en el primer caso uno identifica a una persona con un organismo. En los otros dos las personas vienen a ser dependientes de ciertos organismos, pero no son idénticos a ellos. Si uno sostiene que las personas son sustancias inmateriales dotadas únicamente de propiedades mentales -aunque estén conectadas causalmente a un cuerpo de un modo 'muy íntimo'-, no pueden estar las condiciones de identidad de una persona determinadas por las condiciones de identidad de un organismo. Por otra parte, si las condiciones de identidad de una persona están determinadas por la continuidad de estados psicológicos, comoquiera que tal 'continuidad' sea entendida, entonces la identidad del organismo debe ser irrelevante para la identidad de la persona y no podría afirmarse que una persona es lo mismo que un organismo. Hay, por tanto, una conexión estrecha entre las condiciones de identidad postuladas para una persona y la ontología de la persona, pero no se trata de una relación biunívoca. Por este motivo, no debe extrañar que el fracaso de la teoría psicológica deje varias alternativas abiertas para comprender la ontología de la persona.

\section{El contenido normativo del concepto de persona}

LOCKE ESTÁ EN LO CORRECTO cuando sostiene que el concepto de 'persona' es primariamente un concepto 'forense' (Locke, 1690, II, ch. 27, 26). Al menos en su origen, tiene que ver con criterios para que alguien pueda ser sujeto de imputación de derechos y obligaciones en un sistema jurídico. Se ha sostenido en nuestra tradición filosófica que las personas son 'fines en sí mismos' y que poseen una 'dignidad' que exige el respeto de prohibiciones morales absolutas. Caben en abstracto al menos dos actitudes respecto de este contenido normativo del concepto de 'persona'. En primer lugar, uno podría suponer que se trata de consecuencias de cuestiones ontológicas y ciertos principios de ética normativa que son más

9 Hay aquí puntualizaciones importantes que hacer respecto de estos dos supuestos que se harán más adelante. Si una persona está constituida por un organismo u otro, no puede ser la identidad del organismo determinante de la identidad de la persona. Solo sucede tal cosa si la persona está constituida por un único organismo del que es ontológicamente dependiente. Quienes postulan que las personas están constituidas por organismos típicamente sostienen que no dependen de un único organismo. 
básicos. Desde esta perspectiva, las cuestiones normativas no deben afectar en lo más mínimo la decisión puramente teórica acerca de qué sea una persona y cuáles sean sus condiciones de identidad. Si la ontología de la persona que resulte vindicada es, a fin de cuentas, incompatible con el contenido normativo usualmente atribuido a las personas, tanto peor para esas creencias usuales. Uno puede, sin embargo, adoptar una perspectiva diferente, desde la cual se podría suponer, en primer lugar, que esas tesis normativas han de funcionar como criterios de adecuación acerca de qué sea una persona y qué condiciones de identidad deban serle asignadas, del mismo modo en que uno podría suponer que, por ejemplo, un requerimiento de una teoría adecuada de qué sea una persona sea el que las personas han de resultar entidades concretas y no abstractas. Esto es, se podría suponer que si resulta de una teoría de la persona que las atribuciones normativas que hacemos respecto de las personas son falsas, tenemos un motivo a priori para rechazar tal teoría. Por esta razón, en el presente artículo se adopta la segunda actitud.

Si estuviésemos en una situación en donde -desde un punto de vista epistemológico- tuviésemos gran claridad acerca de la ontología de la persona y gran incertidumbre respecto de las cuestiones normativas, habría motivos para adoptar la primera actitud. En una situación así parece una recomendación sensata tratar de despejar las cuestiones normativas desconocidas usando como punto de apoyo lo conocido. Pero no estamos en tal situación. Mi intuición personal -y creo que la del grueso de mis pares culturales- es que es mucho más claro que las personas poseen una dignidad que exige el respecto de prohibiciones absolutas que, por ejemplo, si las personas son o no organismos o secuencias de estados psicológicos. Por lo menos, no parece plausible que se desechen las intuiciones normativas al concebirlas como menos firmes que ciertas intuiciones ontológicas. Si se quiere, tanto unas como otras deben ser ponderadas a la hora de buscar un equilibrio reflexivo. Debemos tratar de que nuestras teorías sean capaces de sustentar todas o la mayoría de nuestras intuiciones pre-teóricas acerca de las personas. Por supuesto, en algún caso, tendremos razones para rechazar una intuición por las ventajas que ofrece una teoría de un gran poder explicativo con las que esa intuición está en conflicto. En otros casos, el conflicto debe resolverse con el rechazo de la teoría o, por lo menos, su reforma. Todas las intuiciones pre-teóricas deben entrar en estas ponderaciones. Las intuiciones normativas no son de menos valor, en principio, que cualquier otra. 
¿Cuáles son tales intuiciones normativas? Tienen que ver con la atribución de una 'dignidad' a las personas, según la cual está prohibido matarlas, lesionarlas física o psíquicamente, impedir o coartar su libertad, mentirles y desinformarlas, dañar su honor, violar su privacidad, etc. Estas son las garantías usualmente conocidas como 'derechos humanos ${ }^{\text {'10. }}$. Hay restricciones importantes que derivan de estas prohibiciones. En efecto, para que tenga sentido la prohibición normativa de hacer que a, debe ser metafísicamente posible hacer que a. No tiene ningún sentido prohibir que, por ejemplo, se construyan edificios que no son edificios. No es metafísicamente posible algo que satisfaga la descripción de ser un edificio que no es un edificio. Nada puede ser un edificio y no ser un edificio. Entonces no hay acciones metafísicamente posibles que alguien podría realizar para construir algo que satisfaga tal descripción. Esto hace que una prohibición de acciones de tal tipo carezca de sentido. Para el objetivo del artículo, resulta que -si nuestras intuiciones normativas son correctas- debe ser metafísicamente posible matar a una persona, lesionarla física o psíquicamente, dañar su honor, violar su vida privada y mentirle, entre otros supuestos. Pero no es obvio que estos supuestos sean metafísicamente posibles bajo cualquier ontología de la persona.

Considérense ahora las teorías en donde la persistencia de las personas en el tiempo es una cuestión de perduración (Lewis, 1976). Ninguna persona existe estrictamente más que un único instante de tiempo. Lo que hace que nos parezca que las personas persistan en el tiempo es que consideramos fusiones mereológicas de personas de duración instantánea que guardan entre sí cierta semejanza en aspectos que nos parecen relevantes. Hay otras concepciones donde lo que interesa no es la identidad sino la 'supervivencia' (Parfit, 1971; 1984). Una persona es 'superviviente' respecto de otra si y solo si existe una suficiente semejanza entre una y otra en lo que respecta a sus estados mentales y a sus rasgos corporales.

10 Ha sido habitual asociar estas prohibiciones con teorías éticas de tipo deontologista y no con enfoques consecuencialistas. Es efectivo que en los enfoques consecuencialistas siempre hay circunstancias posibles en que el curso de acción moralmente correcto será violar tales prohibiciones. Aún en estas concepciones, sin embargo, se espera que sea un resultado de las teorías propuestas que solo en circunstancias muy excepcionales suceda tal cosa. Los consecuencialistas asumen como criterio de adecuación de sus teorías que estas intuiciones normativas resulten validadas para la gran mayoría de los casos. Resulta, por lo tanto, que estas intuiciones normativas no son exclusivamente deontologistas. Se trata de intuiciones ampliamente compartidas por todas las grandes familias de teorías de ética normativa. 
Tanto Lewis como Parfit tienen como principal motivación para sus teorías el fracaso de las concepciones tradicionales de la identidad personal como continuidad psicológica. ¿Según este tipo de concepciones, cómo puede uno 'matar' a una persona? Hay una noción de sentido común acerca de qué es 'matar' a una persona en la que resulta imposible matar a nadie. Tanto Lewis como Parfit están pensando que no hay algo así como identidad entre dos personas en diferentes instantes de tiempo. Cada persona persiste estrictamente un instante puntual de tiempo. 'Matar a $x$ ' en la concepción ordinaria es hacer que $x$-que existía en instantes de tiempo anteriores- ya no lo haga. Se supone que $x$ en los instantes anteriores es idéntico a $x$ en los instantes posteriores. Pero en estas propuestas ninguna persona dura más de un instante. Querer matar a una persona es tan absurdo como querer hacer que un instante puntual de tiempo no dure más de un instante puntual de tiempo. Es trivial que todo instante puntual de tiempo dure un instante puntual de tiempo. Nada que uno pueda hacer impide que sea así, y nada que uno pueda hacer tiene la menor eficacia para hacer que sea así. De un modo semejante, la prohibición de matar a una persona sería absurda, pues nada que uno pueda hacer tendrá ninguna eficacia para hacer que una persona deje de existir. Nada tampoco que uno pueda hacer tiene eficacia para impedir que una persona deje de existir.

Uno podría, sin embargo, tratar de re-interpretar de manera apropiada el concepto de 'matar a alguien' para que las concepciones de Lewis o de Parfit se adecúen a nuestras intuiciones normativas. En el caso de Lewis, lo que se está sosteniendo es que las personas persisten en el tiempo por tener diferentes partes temporales. Uno podría interpretar, entonces, que 'matar a $x$ ' es 'hacer que $x$ deje de persistir'. Esto es, es hacer que deje de tener partes temporales para tiempos futuros respecto de cierto instante. Pero, ¿cómo podría uno hacer que algo no tenga partes temporales futuras? Una fusión de partes temporales viene dada automáticamente en mereología -al menos, mereología extensional estándar ${ }^{11}$ por el mero hecho de existir sus partes. Si aquello que compone la fusión son personas de duración instantánea, basta con que esas personas existan para que exista su fusión. Intervenir sobre una fusión mereológica de personas de

11 La mereología extensional estándar suele ser caracterizada por tres postulados: (i) la relación 'ser parte de' es transitiva; (ii) dos sumas mereológicas son idénticas si y solo si tienen las mismas partes (unicidad de composición); y (iii) dados objetos $x_{1}, x_{2}, \ldots, x_{\mathrm{n}}$ existe la fusión de $x_{1}, x_{2}, \ldots, x_{\mathrm{n}}$ (sumas mereológicas irrestrictas). Véase: Lewis, 1991, p. 74. 
duración instantánea es intervenir sobre una o más de tales personas. Después de todo, la fusión está fundada ontológicamente en sus partes. Pues bien, uno no puede matar a una persona de duración instantánea presente o pasada. Y si se trata de impedir que existan personas instantáneas futuras, se trata, en efecto, de personas futuras sobre las que tampoco podemos tener eficacia causal alguna ${ }^{12}$. Resulta, de nuevo, que nada que nosotros podamos hacer es apto para matar a una persona. Entonces, su prohibición resultaría absurda. En el caso de Parfit, lo que se está sosteniendo es que la identidad no es realmente importante para la supervivencia. Todo lo que interesa es cierta continuidad gradual entre diferentes personas instantáneas en lo psicológico y en lo físico. Aquí debería re-interpretarse el concepto de 'matar' como impedir que alguien tenga algún superviviente. Pero, nuevamente, ¿cómo podría uno hacer tal cosa? No hay intervención que podamos efectuar sobre las personas de duración instantánea presentes y mucho menos sobre las pasadas. Pero tampoco podemos intervenir sobre las personas futuras, ya que son estas personas instantáneas las que deberían ser supervivientes unas respecto de las otras. Hacer que alguien no tenga supervivientes debe ser intervenir sobre las personas instantáneas que se encuentran en tal relación. Entonces, aunque se acepte una re-interpretación como la indicada, no nos sería posible metafísicamente matar a una persona. Por tanto, la prohibición de matar a alguien sería absurda.

Esto que vale para la prohibición de matar, vale también para las prohibiciones de lesionar física o psíquicamente, mentir, dañar el honor, etc. Nuestras intuiciones normativas acerca de las personas parecen presuponer que estas enduran en el tiempo, siendo idénticas en diferentes instantes de tiempo. Solo así, por ejemplo, el daño que hacemos a una persona en un tiempo $t$ afecta a la

12 Un problema adicional tiene que ver con el hecho de que las fusiones mereológicas son arbitrarias. No se requiere ningún tipo de conexión entre las partes para conformar el todo. Una persona persistiendo en el tiempo es simplemente una fusión mereológica de personas de duración instantánea. Una misma persona instantánea integrará fusiones con todas las otras personas instantáneas de otros instantes de tiempo. No hay ningún privilegio para alguna de esas fusiones por sobre otras. Una persona persistiendo en el tiempo puede estar integrada por las personas instantáneas que asociamos a Cleopatra hasta su cumpleaños número 13 y luego por las personas instantáneas que asociamos a Napoleón desde su cumpleaños número 13. Entonces sucede que el único modo en que se podría impedir que una persona instantánea deje ser parte de una persona que persiste en algún instante futuro sería aniquilando toda persona instantánea futura. 
misma persona que existe en otros tiempos. Estos son motivos suficientes para afirma que es parte del concepto de 'persona' que esta debe ser idéntica en el tiempo. Cualquier concepción que rechace este dato básico ha dejado de postular la existencia de personas. Así, uno no puede suponer de entrada que las intuiciones normativas que parecen imponer esta conclusión tienen menos valor que cualquier otra intuición ontológica.

\section{El programa de reducción psicológica de la persona}

LA TEORÍA PREVALENTE DE LA IDENTIDAD PERSONAL ha sido la teoría psicológica. De un modo grueso, en este tipo de concepción las condiciones de identidad de una persona vienen dadas por la continuidad psicológica entre las diferentes 'etapas personales', al menos en lo que concierne a la persistencia temporal. Se designará como 'etapa personal' de la persona $x$ en el tiempo $t$ a $x$-en-t. Como suponemos que las personas enduran en el tiempo, $x$ existirá, toda entera, en más de un instante de tiempo. Las condiciones de identidad -temporales- de una persona vendrían dadas por el siguiente principio:

- Continuidad psicológica: es necesario que para toda persona $x, y: x$-en- $t_{1}$ $=y$-en- $t_{2}$ si y solo si $y$-en- $t_{2}$ es psicológicamente continuo con $x$-en- $t_{1}$.

Hay una larga tradición filosófica en donde las personas se han considerado sustancias con capacidades racionales y dotadas de libertad. La teoría psicológica ha descansado en una peculiar forma de interpretar tal tradición ${ }^{13}$. Si lo que hace que una persona sea una persona son sus estados mentales, entonces pareciese que la identidad de las personas debería tener que ver con el carácter intrínseco de estos. ¿En qué consiste la 'continuidad psicológica'? De un modo muy especial, consiste en los estados de memoria. Esto es, uno estaría inclinado a sostener que si la etapa personal $x_{1}$-en- $t_{1}$ es continua psicológicamente con la etapa personal $x_{2}$-en$t_{2}$, entonces $x_{1}$-en- $t_{1}$ recuerda experiencias que $x_{2}$-en- $t_{2}$ ha tenido. Por supuesto, no

13 En un famoso pasaje, Locke señala que persona "es un ente pensante, inteligente, que posee razón y reflexión, y que puede considerarse a sí mismo como sí mismo, la misma cosa pensante (thinking thing) en diferentes tiempos y lugares" (Locke, 1690, II, ch. 27, n. 9). Hay aquí una resonancia de la forma en que Descartes caracteriza al alma, mente o espíritu como res cogitans (Descartes, 1641, AT VII, 27). Y hay obviamente una resonancia de la tradición escolástica donde una persona era caracterizada como rationalis naturae individua substantia siguiendo a Boecio (ML 64, 1343c). 
serviría aquí que uno recordase lo que ha hecho una persona en el pasado, si el recuerdo no tiene que ver con las experiencias que ella ha tenido desde su perspectiva de primera persona. Uno podría recordar, en efecto, lo que otra persona ha hecho, pero no qué experiencias ha tenido tal persona al hacer lo que ha hecho. Es lo segundo lo relevante para la teoría psicológica. Junto a los estados de memoria que conecten entre sí las diferentes etapas personales, también debe suponerse cierta continuidad en las creencias, preferencias, intenciones y rasgos de carácter.

Supóngase que un príncipe amanece un día sin recordar nada de lo que ha hecho en su vida anterior, sin las mismas creencias, sin las mismas intenciones y sin las mismas preferencias. Recuerda, sin embargo, con todo detalle las experiencias pasadas de un zapatero. Posee las mismas creencias, intenciones y preferencias del zapatero, así como sus rasgos de carácter. El zapatero, por su parte, amanece también sin recordar ninguna de sus experiencias anteriores, pero recordando con todo detalle las experiencias pasadas del príncipe. Del mismo modo, ha perdido todas sus antiguas creencias, intenciones y preferencias, pero tiene ahora las mismas que las del príncipe. La intuición central de la teoría psicológica es que en un caso así la persona que se encuentra en el cuerpo del príncipe es el zapatero, y la persona que se encuentra en el cuerpo del zapatero es el príncipe. De un modo análogo, supóngase que en el futuro fuese posible hacer trasplantes de cerebro de un modo exitoso. Supóngase que se extrae el telencéfa$10^{14}$ del señor Pérez y se implanta en el cuerpo del señor González. El cuerpo del señor Pérez se mantiene vivo en estado vegetativo por permanecer ahí el diencéfalo del señor Pérez. ¿Quién es ahora el señor Pérez? La intuición de los defensores de la teoría psicológica es que Pérez es quien ahora está en el cuerpo de González. Es lo que está ahí lo que reconoceríamos como Pérez si pudiésemos conversar con él acerca de, por ejemplo, sus recuerdos de la infancia.

Hay una multitud de refinamientos de estas intuiciones centrales. Un primer problema que ha debido ser enfrentado por las teorías psicológicas es que apelar a la memoria para fijar las condiciones de identidad de una persona, al menos en lo temporal, parece circular. En efecto, parece una condición necesaria

14 El telencéfalo es la estructura cerebral que cumple las funciones más altas de integración somática y es responsable de las funciones cognitivas superiores. Se encuentra sobre el diencéfalo que es responsable de la integración de funciones vegetativas. 
para que $x$ recuerde la experiencia de $y$, que $x=y$. Algunos han planteado como forma de resolver esta cuestión que se fijen las condiciones de identidad personal en términos de 'cuasi-memoria' y no en términos de memoria, en donde el requerimiento de identidad se deja a un lado (Shoemaker, 1970; Noonan, 2003, pp. 144-162). Otro problema tradicional es que la continuidad psicológica no es una relación transitiva, pero la identidad sí lo es. Perfectamente puede suceder que $x_{1}$-en- $t_{1}$ tenga continuidad psicológica con $x_{2}$-en- $t_{2}$, y $x_{2}$-en- $t_{2}$ tenga continuidad psicológica con $x_{3}$-en- $t_{3}$, pero no sea el caso que $x_{1}$-en- $t_{1}$ tenga continuidad psicológica con $x_{3}$-en- $t_{3}$. Un anciano de 80 años podría recordar sus experiencias cuando tenía 40 años, y el hombre de 40 años podría recordar sus experiencias cuando tenía 15 años, sin que el anciano recuerde las experiencias del adolescente de $15 \mathrm{años}^{15}$. Parece más razonable, por esto, formular la teoría psicológica en términos del ancestral de la relación de continuidad psicológica, sea continuidad psicológica*. La etapa personal $x_{1}$-en- $t_{1}$ es continua psicológicamente ${ }^{*} \operatorname{con} x_{3}$-en- $t_{3}$ si y solo si $x_{1}$-en- $t_{1}$ es continua psicológicamente con $x_{3}$-en- $t_{3}$, o hay una etapa personal $x_{2}$-en- $t_{2}$ tal que: $x_{1}$-en- $t_{1}$ es continua psicológicamente $\operatorname{con} x_{2}$-en- $t_{2}, \mathrm{y} x_{2}$-en- $t_{2}$ es continua psicológicamente con $x_{3}$-en- $t_{3}$; o bien hay una etapa personal $x_{\mathrm{i}}$-en- $t_{\mathrm{i}}$ tal que: $x_{1}$-en- $t_{1}$ es continua psicológicamente con $x_{2}$-en$t_{2}$, y $x_{2}$-en- $t_{2}$ es continua psicológicamente con $\ldots x_{\mathrm{i}}$-en- $t_{\mathrm{i}}$, y $x_{\mathrm{i}}$-en- $t_{\mathrm{i}}$ es continua psicológicamente con $x_{3}$-en- $t_{3}$, etcétera. No interesan aquí demasiado estos detalles. En lo que sigue se va a suponer que hay una formulación aceptable de la teoría psicológica que puede resolver estas cuestiones.

Las dificultades más graves para la teoría psicológica han tenido que ver con supuestos de 'fisión' de personas que parecen incompatibles con una auténtica relación de identidad. La identidad es una relación uno-a-uno, y no uno-a-muchos. Esto es una consecuencia del carácter reflexivo, simétrico y transitivo de la identidad. Supóngase que $x=y, x=z$. No puede ser que $y^{1} z$. Si $x=y$, por simetría, $y=$ $x$. Luego por transitividad, $y=z$, contra la hipótesis. La teoría psicológica de la identidad personal, sin embargo, parece dejar espacio para casos de fisión de personas. Un tipo de escenario muy citado es el del trasplante de los hemisferios

15 Cosas todavía más extrañas podrían suceder. El anciano de 80 años podría no recordar las experiencias del hombre de 40 años, pero sí recordar las experiencias del adolescente. Para una presentación de supuestos de este tipo y otros refinamientos, véase: Perry, 2008b, pp. 16-20. 
cerebrales (Nagel, 1971). Hay casos en que una persona ha sufrido la destrucción de uno de sus hemisferios cerebrales, pero ha podido mantener continuidad psicológica con el hemisferio restante. Si fuese posible hacer trasplantes de cerebro, entonces podrían extirparse los dos hemisferios cerebrales del señor Pérez y trasplantarse el derecho en el cuerpo del señor González y el izquierdo en el cuerpo del señor Rojas. Si los trasplantes fuesen exitosos, resultaría que Pérez sería psicológicamente continuo con González -o lo que resulta del trasplante en el cuerpo de González- y también psicológicamente continuo con Rojas -o lo que resulta del trasplante en el cuerpo de Rojas. Es claro que González ${ }^{1}$ Rojas. Pero según el principio de Continuidad psicológica debería resultar que Pérez = González y Pérez $=$ Rojas, con lo que debería seguirse que González $=$ Rojas. Hay detalles que podrían discutirse acerca de un escenario como este ${ }^{16}$, pero la cuestión central no depende realmente de tales detalles asociados con trasplantes de cerebro. Es metafísicamente posible que una persona cambie sus creencias, sus intenciones, sus preferencias y sus rasgos de carácter. Es posible que una persona crea recordar por error haber tenido una experiencia que no ha tenido. Es posible que una persona olvide haber tenido una experiencia que ha tenido. Entonces, parece también metafísicamente posible que González modifique sus estados psicológicos de tal modo que llegue a ser psicológicamente continuo con Pérez. Como también es esto posible respecto de Rojas -y no hay ninguna razón para rechazar la composibilidad de ambos escenarios-, es metafísicamente posible que tanto González como Rojas lleguen a ser psicológicamente continuos y en el mismo grado con Pérez, mientras que Pérez sufre al mismo tiempo una amnesia total.

Este parece ser un caso en donde se muestra la insuficiencia de la continuidad psicológica como principio de identidad. Hay varias estrategias que han sido intentadas para resolver este problema. Se ha sostenido, por ejemplo, que debe preferirse al 'mejor candidato' en situaciones en que se presenten fisiones como la indicada. Si hay un trasplante de hemisferios cerebrales debería preferirse a aquel

16 Por ejemplo, la Dra. Rommy von Bernhardi me ha hecho notar que nunca los dos hemisferios cerebrales son perfectamente simétricos. En un caso como el descrito, aunque exista continuidad psicológica entre Pérez tanto con González como con Rojas, existirán diferencias entre sus estados psicológicos globales que permitirían, eventualmente, establecer un ranking de mayor o menor continuidad psicológica entre González y Rojas respecto de Pérez. Algunos se han apoyado en estas diferencias para sostener que debe preferirse el 'mejor candidato'. Este refinamiento de la teoría psicológica se tratará más adelante. 
que resulte tener la 'mayor' continuidad psicológica ${ }^{17}$. Una maniobra de este tipo, sin embargo, no bloquea los casos en que hay perfecta simetría entre los candidatos. Sucede también que no parece razonable hacer depender la identidad entre dos entidades de hechos extrínsecos a los relata. Si $x=y$, este hecho debe tener que ver solamente con $x$ e $y$ (Noonan, 2003, pp. 127-143, 214-231). Considérese lo que sucedería de otro modo. Se ha hecho con éxito el trasplante de los hemisferios cerebrales de Pérez a los cuerpos de González y de Rojas. Se hace un ranking entre estos y resulta que González es más continuo psicológicamente con Pérez. Entonces la persona en el cuerpo de González = Pérez. Supóngase ahora que el trasplante resulta mal en el cuerpo de González y la persona ahí muere. En un caso así, resultaría que el mejor candidato en lo que respecta a continuidad psicológica sería la persona en el cuerpo de Rojas. Entonces ahora Pérez = la persona en el cuerpo de Rojas. Pero la situación en lo que es referente a los estados mentales de Pérez y a los estados mentales en la persona en el cuerpo de Rojas es exactamente la misma que en el escenario en que Pérez ${ }^{1}$ la persona en el cuerpo de Rojas. Si realmente lo único relevante para la identidad personal es la continuidad psicológica no se ve por qué en un caso los mismos hechos determinan identidad y en otro no. Otros han sostenido que en un caso de fisión en donde no exista un mejor candidato debe suponerse que la persona fisionada no es idéntica a ninguno de los resultantes de la fisión. Pero esto nuevamente sería muy extraño. Sea que se hace con éxito el trasplante de hemisferios cerebrales de Pérez en González y Rojas, y ninguna de las personas resultantes es más continua con Pérez que la otra. Resultaría, si se sigue la recomendación citada, que Pérez ${ }^{1}$ la persona en el cuerpo de González y Pérez ${ }^{1}$ la persona en el cuerpo de Rojas. Supóngase ahora que el trasplante en el cuerpo de González fracasa. Entonces ahora Pérez = la persona en el cuerpo de Rojas. Pero no hay aquí ninguna variación en cuanto a los estados psicológicos de Pérez y de la persona en el cuerpo de Rojas. Si realmente lo único relevante para la identidad personal son los estados

17 ¿Cómo habría de hacerse un ranking de continuidad psicológica? Hay diversos respectos que pueden estar en competencia entre sí. Si hay dos candidatos a ser la persona $x$, sean $y$ y $z$, puede suceder que $y$ comparta más recuerdos de la infancia de $x$, pero $z$ tenga más recuerdos de la edad adulta. Puede suceder que $y$ recuerde más episodios, pero $z$ tenga recuerdos más vívidos y detallados. Puede suceder que $y$ tenga más recuerdos, pero $z$ comparta más creencias, intenciones, preferencias y rasgos de carácter, etc. 
psicológicos no se entiende que los mismos hechos acerca de estados psicológicos en un caso determinan que sí hay identidad y en otro no.

No solo hay problemas con la suficiencia del principio de Continuidad psicológica, también los hay respecto de su necesidad. Esto es, parece que aunque no exista continuidad psicológica sí hay identidad personal. Un escenario de este tipo no es difícil de concebir. Tal como se ha explicado más arriba, es metafísicamente posible que alguien cambie sus creencias, intenciones, preferencias y rasgos de carácter. Es metafísicamente posible que alguien olvide las experiencias que ha tenido en el pasado. Es metafísicamente posible que alguien equivocadamente crea recordar experiencias pasadas que no ha tenido. Nada parece impedir la composibilidad de estas diferentes posibilidades. Entonces, parece metafísicamente posible que una persona no sea continua psicológicamente entre dos instantes de tiempo. Por supuesto, si hay etapas personales intermedias que permitan conectar entre sí esos dos instantes de tiempo, habría, de todos modos, continuidad psicológica* entre ellos. Pero nada impide la posibilidad metafísica de un cambio tan brusco en los estados psicológicos de una persona tal para que no exista dicha continuidad*. Debería seguirse en estos casos que no hay identidad entre las etapas personales discontinuas psicológicamente entre sí de acuerdo con el principio de Continuidad psicológica. Pero parece obvio que sí habría identidad. Se ha dicho que consideraciones 'forenses' son un apoyo para la teoría psicológica de la identidad personal. Aquí, sin embargo, se puede apreciar que la situación es exactamente la opuesta: son precisamente consideraciones forenses las que ponen de relieve la falla del principio de Continuidad psicológica. Supóngase que el señor Pérez comete un crimen nefando en $t_{1}$. Pasa el tiempo y en $t_{2}$ el señor Pérez tiene una transformación interior profunda. Olvida gran parte de sus experiencias anteriores y cambia sus creencias, intenciones, preferencias y rasgos de carácter. Si antes era un criminal, ahora es un ciudadano respetuoso de las leyes y comprometido con su comunidad. Supóngase que la Fiscalía llega a determinar la culpabilidad del señor Pérez en $t_{3}$ al aparecer evidencia suficiente para incriminarlo. ¿Sería legítimo que el señor Pérez se excuse sosteniendo que ahora es 'otra persona'? ¿Tendría aquí relevancia que el señor Pérez haya olvidado el crimen cometido en $t_{1}$ ? Todo esto parece completamente irrelevante. Por supuesto, puede haber consideraciones que un tribunal podría tener en cuenta para conceder medidas alternativas de cumplimiento de la pena debida por el crimen, 
pero no parece de ningún modo que en $t_{3}$ el señor Pérez no sea responsable del crimen que cometió.

Esto es suficiente para rechazar la teoría psicológica y otras cercanas ${ }^{18}$. Hay otros motivos que han sido aducidos a favor de la teoría psicológica, pero parecen ya suficientemente contestados en otros sitios (Olson, 1997, pp. 42-72; Snowdon, 2014, pp. 125-237). En una addenda se van a discutir ciertas consideraciones modales adicionales en contra de la teoría psicológica. La situación en la que nos encontramos es que la teoría psicológica debe ser rechazada. Esto obliga a considerar las alternativas teóricas abiertas para comprender las condiciones de identidad de las personas y, con ello, las alternativas abiertas para concebir la naturaleza de las mismas. Consideraremos esto a continuación.

\section{4. ¿̇Animales o ángeles?}

De ACUerdo Con lo QUe SE HA ARgumentado hasta este punto, las personas no pueden ser reducidas a fusiones mereológicas de etapas temporales instantáneas. Es parte de nuestro concepto de persona que deben ser entidades aptas, por su naturaleza, para endurar en el tiempo siendo la misma en diferentes instantes. Por otro lado, las condiciones de identidad de una persona no pueden ser fijadas por algún criterio psicológico. Tal como se ha mostrado, la teoría psicológica de la identidad personal tiene resultados desastrosos. ¿Qué alternativas quedan abiertas para entender la naturaleza de las personas y las condiciones de identidad personal? $\mathrm{Al}$ parecer, hay dos tipos de alternativas teóricas abiertas: una sustancia -eventualmente inmaterial- con condiciones de identidad primitivas, o un organismo biológico. Se trata de 'tipos' de alternativas teóricas, pues

18 Un tipo de teoría cercana a la teoría psicológica es la concepción según la cual las personas están constituidas por organismos biológicos, pero no son organismos biológicos (Johnston, 1987; Baker, 2000). En esta concepción la identidad de una persona en el tiempo no requiere que persista el mismo organismo. Todo lo que se requiere es que exista algún organismo en el que la persona esté constituida. La relación que existe entre una persona y el organismo biológico que lo sustenta es análoga a la relación que tiene una estatua con el pedazo de bronce de que está hecha. En los casos en que, por ejemplo, se hace un trasplante de cerebro, la teoría de la constitución preserva las intuiciones típicas de la teoría psicológica: la persona persiste en quien preserva continuidad psicológica. Esto basta para rechazar estas teorías, si es que hay motivos - tal como se ha explicadopara rechazar principios de identidad como los indicados en Continuidad psicológica. Para otras críticas a la teoría de la constitución, véase: Olson, 2007, pp. 48-75. 
hay múltiples teorías específicas que podrían desarrollarse bajo cualquiera de estos tipos generales. En lo que sigue se presentarán estas dos grandes familias de concepciones. No se pretende hacer aquí una adjudicación entre ellas, aunque es inevitable que una presentación, aunque sea modesta, no puede dejar de poner de relieve costos y ventajas teóricas de cada una, las que son relevantes para preferir alguna en particular, eventualmente.

\subsection{ORGANISMOS BIOLÓGICOS}

UNA ALTERNATIVA TRADICIONAL a la teoría psicológica de la identidad personal es el llamado 'criterio corporal' o 'físico' de identidad. La identidad de una persona en el tiempo estaría determinada por la continuidad del mismo 'cuerpo'. La tesis de que las personas -al menos, las personas humanas ${ }^{19}$ - son organismos biológicos, sin embargo, no debe ser confundida con el antiguo criterio 'físico'. Ningún organismo vivo está constituido por las mismas partículas en diferentes tiempos. Es propio de un organismo, en efecto, estar en un constante intercambio de nutrientes y desechos metabólicos con su ambiente. Un organismo biológico no puede ser identificado, por lo tanto, con un pedazo de materia -comoquiera que sea entendido qué sea 'materia'. Se ha denominado como 'animalismo' la tesis según la cual las personas son organismos biológicos y las condiciones de identidad de una persona son las condiciones de identidad de un organismo (Olson, 1997; 2003; 2007, pp. 23-47; Snowdon, 2014; van Inwagen, 1990, pp. 81-97, $115-123,142-212)$. Es característico en estas concepciones que las intuiciones fundamentales que han sido la guía de la teoría psicológica son aquí revertidas. Supóngase que al señor Pérez le extraen el telencéfalo y se lo trasplantan al cuerpo del señor González. Los defensores de la teoría psicológica han sostenido que la persona que se encuentra en el cuerpo del señor González es Pérez y no González. Y lo que se encuentra en el cuerpo del señor Pérez ya no es una persona en absoluto. Pues bien, si las personas humanas somos organismos, entonces en este caso deberíamos sostener exactamente lo inverso. Lo que se encuentra en el organismo del señor Pérez es Pérez. El hecho de que no pueda ahora desplegar capacidades cognitivas superiores no hace que deje de existir. ¿Y qué sucede con González?

19 Por supuesto, si uno admite como personas también ángeles o las tres personas divinas -tal como sucede en la Teología Cristiana- no puede suponerse que las condiciones de identidad personal de estas entidades sean las de un organismo biológico. 
Ha recibido un cerebro diferente, pero esto es tan relevante para su identidad personal como el haber recibido un trasplante de hígado. La persona que se encuentra en el cuerpo de González sigue siendo González. El hecho de que haya sufrido una perdida masiva de memoria no hace que González muera. En el clásico caso del príncipe y el zapatero, por otra parte, es irrelevante que el príncipe haya olvidado todo lo que ha hecho anteriormente. Esto sucede también cuando alguien sufre amnesia. Es irrelevante que el zapatero haya olvidado también todo lo que ha hecho anteriormente. Es irrelevante que el príncipe crea recordar todo lo que ha hecho el zapatero y que el zapatero crea recordar todo lo que ha hecho el príncipe. Los cambios de memoria y las modificaciones de otros estados mentales tales como creencias, preferencias, intenciones y rasgos de carácter no fijan los hechos de identidad. Lo relevante son las condiciones que fijan la identidad de un mismo organismo biológico. Si el organismo del príncipe es el mismo antes y después de la pérdida masiva de memoria, entonces la persona que luego recuerda todo lo que ha hecho el zapatero sigue siendo el príncipe.

La teoría 'animalista' tiene importantes consecuencias. Si la identidad de una persona tiene que ver con la identidad del mismo organismo, entonces todos nosotros hemos sido alguna vez un embrión y luego un feto (Olson, 1997, pp. 73-93). En la teoría psicológica solo puede uno admitir la existencia de una persona cuando tenemos algo que es sujeto de estados mentales conscientes y que puede estar conectado a otras etapas personales con memoria de las experiencias anteriores. Por lo tanto, en la teoría psicológica ningún feto podría contar como una persona. De un modo semejante, si alguien llega a quedar en estado vegetativo o sufre una pérdida masiva de memoria, esto no hace que la persona desaparezca. Ha sido frecuente utilizar como criterio de muerte el cese de la actividad cerebral. Es una consecuencia de la teoría 'animalista' que este criterio debe aplicarse con extremada cautela. Si el cese de actividad cerebral no está ligado al cese de la vida del organismo -lo que incluye el cese de todas las funciones vegetativas- no estaríamos en presencia de la muerte de la persona. Una persona en estado vegetativo o en un coma prolongado sigue siendo una persona, y la misma persona numéricamente que la persona antes de caer en tal estado.

La teoría 'animalista' sería el candidato más razonable para sustituir a la teoría psicológica, si es que hubiese claridad acerca de qué es un organismo biológico y cuáles son sus condiciones de identidad. Pero se trata de cuestiones todavía 
no resueltas a satisfacción de todos. Los organismos parecen persistir en el tiempo incorporando diferentes componentes orgánicos en diferentes tiempos. No puede uno, por lo tanto, fijar la identidad de un organismo por las moléculas que lo componen, u otras partes materiales. Un organismo crece o decrece en el tiempo y, para un instante dado, podría haber sido un poco más grande o un poco más pequeño. Esto implica que varía permanentemente sus propiedades determinadas ${ }^{20}$ en el tiempo. Un vegetal tendrá diferentes formas, diferentes masas y diferentes longitudes espaciales en diferentes tiempos. Para un mismo tiempo tiene una masa, una forma y unas longitudes determinadas, pero podría haber tenido otras diferentes. Ninguna de tales propiedades, por lo tanto, podría estar integrando sus condiciones de identidad. Típicamente, además, un organismo biológico estará constituido por diferentes 'materias'. Para hacer inteligible un organismo se requiere postular una relación de 'constitución' entre el organismo y los materiales que lo constituyen, y con los que ha de ser numéricamente diferen$\mathrm{te}^{21}$. Todo lo que sabemos es que los organismos vivos mantienen un equilibrio dinámico con su ambiente circundante. Lo que mantiene la vida de un organismo es la continuidad de los procesos metabólicos que son intercambios de materiales. Los organismos también mantienen tal equilibrio dinámico, esto es, se trata de algo que uno puede imputar a un organismo como a su agente. Al hacer esto, los organismos parecen estar guiados por la consecución de una finalidad.

20 Una propiedad 'determinada' por oposición a una propiedad 'determinable' es, por ejemplo, la propiedad de tener exactamente 10 gramos de masa, por oposición a la propiedad de tener alguna masa. Las propiedades determinadas son formas máximamente específicas de poseer una propiedad determinable. Hay relaciones sistemáticas precisas entre las propiedades determinadas y determinables. Si algo tiene una propiedad determinada $P$, entonces debe tener todas las propiedades determinables $Q_{1}, \ldots, Q_{\mathrm{n}}$ que $P$ está determinando. $\mathrm{Si}$ algo tiene una propiedad determinable $Q$, entonces debe tener una y solo una propiedad determinada $P$ bajo ese determinable. Varios filósofos han sostenido que solo existen las propiedades determinadas. Las llamadas 'propiedades determinables' serían simplemente predicados o conceptos, pero no propiedades auténticas (Armstrong, 1978, pp. 111-113, 117-120).

21 Es extraño que Olson (2007, pp. 23-47), luego de presentar el 'animalismo', haga una crítica muy general a las teorías de constitución (Olson, 2007, pp. 48-75). Hay problemas, tal como se ha indicado más arriba, al sostener que las personas están constituidas por organismos -en efecto, se asignarían condiciones de identidad psicológicas a las personas- pero si no hay constitución de ningún modo, tampoco podría haber organismos. Los organismos deben estar constituidos materialmente por moléculas orgánicas con las que no pueden ser identificados. 
Lo más verosímil que poseemos para especificar las condiciones de identidad de un organismo biológico parece ser un principio tal como este:

Continuidad biológica: es necesario que para todo organismo $x, y: x$-en- $t_{1}=$ $y$-en- $t_{2}$ si y solo si la vida de $y$-en- $t_{2}=$ la vida de $x$-en- $t_{1}$. (Olson, 1997 , p. 138)

De un modo análogo, van Inwagen $(1990,90)$ ha sostenido que los $x$ s componen $y$ si y solo si la actividad de los $x$ s constituyen una vida -la vida de $y^{22}$. Pero poseemos tanta claridad acerca de qué es una vida como la que poseemos acerca de qué es un organismo. Hay aquí también problemas adicionales, pues 'la vida de $x$ ' parece ser un evento, cuya persistencia viene dada por la posesión de diferentes partes temporales. Cuando se dice que la vida de $x$-en- $t_{1}=$ la vida de $y$-en- $t_{2}$ no se puede estar sosteniendo que la vida en cuestión es numéricamente idéntica en $t_{1}$ y $t_{2}$. La vida es una complexión de operaciones que mantienen el equilibrio dinámico teleológicamente orientado del organismo. Las operaciones serán numéricamente diferentes para diferentes tiempos. Pueden 'asimilarse' como partes de la misma vida, que ha de ser la fusión mereológica de todas esas operaciones en el tiempo. Para Olson y van Inwagen parece más razonable, entonces, especificar las condiciones de identidad de una vida en términos del organismo - del que constituye la fusión mereológica de todas sus operaciones- y no al revés.

También se ha planteado que podrían darse para organismos biológicos casos de fisión y de fusión, de un modo semejante a como se han presentado para la teoría psicológica ${ }^{23}$. Un caso de fusión sería el de siameses que parecen ser dos personas diferentes pero que compartirían el mismo organismo. Hay casos de siameses que comparten todas las extremidades inferiores desde el ombligo y varios órganos vitales. Así como habría casos de 'fusión' de organismos, también habría casos de 'fisión' cuando se forman gemelos monocigóticos. Aquí, una célula que debería ser parte de un organismo se separa y llega a constituir un organismo independiente. Tal como para la teoría psicológica, estos casos serían fatales para una teoría 'animalista' de la identidad personal. Si hay realmente casos de fisión o fusión de organismos, entonces no es posible identificar a una persona con un

22 Para van Inwagen éste es el único caso de composición material, en que varios objetos llegan a componer como partes otro objeto que resulta de su fusión.

23 Agradezco, en especial, a Gonzalo Génova por haberme planteado esta objeción con algunos casos clínicos muy elocuentes. 
organismo. A diferencia de lo que sucede en el caso de la teoría psicológica, sin embargo, no hay aquí suficiente claridad acerca de qué deba seguirse de estos escenarios. Supóngase que el señor Pérez tuviese una falla en sus riñones y se lo conectase a un riñón del señor González. ¿Esto haría que Pérez y González compartan el mismo organismo biológico? Parece obvio que no. Compartir un órgano no es compartir un organismo. De un modo análogo, los casos más extremos de siameses pueden ser tratados simplemente como casos en que se comparten ciertos órganos, lo que no impide que existan dos organismos biológicos numéricamente diferentes entre sí. Por supuesto, un caso límite en que dos organismos compartan todos sus órganos es un caso en donde no hay dos organismos, sino uno solo, pero un caso así no sería un caso de siameses. Por otro lado, cuando se trata de la 'fisión' que genera gemelos monocigóticos tampoco hay claridad de que se trate de un caso real de fisión de un organismo. De un modo general, un organismo unicelular que se reproduce por mitosis no es idéntico a ninguno de los dos nuevos organismos resultantes. La mitosis trae consigo siempre la muerte del organismo originante. No se ve por qué no deba sostenerse algo así para el caso de los gemelos: una célula pluripotencial que formaba parte de una mórula se separa y -luego de reprogramarse- da lugar a un organismo diferente. Las células de la mórula no separadas deben también reprogramarse para dar lugar a un organismo completo. Esto no es un caso de fisión de la mórula. La mórula inicial no es idéntica a ninguno de los dos organismos resultantes.

Como se puede apreciar, por lo tanto, no existen aquí las dificultades de principio que afectan a la teoría psicológica de la identidad personal, pero sí hay cuestiones que exigen una mayor clarificación y desarrollo.

\subsection{SUSTANCIAS PRIMITIVAS}

UNA SEGUNDA ALTERNATIVA TEÓRICA consiste en sostener que las condiciones de identidad de una persona son primitivas. Recuérdese que no es necesario que las condiciones de identidad de entes de un tipo deban venir fijados por entes de otro tipo. De un modo general, uno debe suponer que -comoquiera que sea la ontología que se proponga- algún tipo de entidad deberá proponerse 
como básico o fundamental ${ }^{24}$, no dependiente de nada. Si uno sostiene, por otra parte, que las condiciones de identidad de las personas vienen dadas por la continuidad psicológica, entonces las personas resultarán dependientes ontológicamente de los estados psicológicos. Si uno sostiene que las condiciones de identidad de las personas vienen dadas por la continuidad biológica de un organismo, entonces las personas resultarán dependientes ontológicamente de organismos biológicos. En abstracto, perfectamente uno podría sostener que las personas son entidades independientes. Sus condiciones de identidad serán, por lo tanto, primitivas. Las personas podrán integrar las condiciones de identidad de otras entidades menos fundamentales, pero no habrá nada que determine las condiciones de identidad de las personas.

Sostener que las personas son entidades fundamentales y que sus condiciones de identidad son primitivas deja abierto todavía muchas formas en que podría ser entendida su naturaleza. Una primera ontología de la persona que podría ser propuesta es una concepción dualista (Swinburne, 1984). Esto es, uno podría sostener que las personas deben ser identificadas con sustancias caracterizadas solo por la posesión de diferentes estados mentales en diferentes tiempos. Estas personas no dependen ontológicamente de ninguna entidad física, o dotada de propiedades físicas. Con lo que no solo se trata de que una persona puede estar 'conectada' a diferentes organismos biológicos respecto de los cuales ha de ser independiente. La persona podría no estar conectada a ningún organismo, podría subsistir de un modo completamente inmaterial ${ }^{25}$. Cuando se sostiene que una persona es una

24 Decir de $x$ que es 'fundamental' es ambiguo entre sostener que (a) no depende ontológicamente de nada, y (b) que no está fundado en nada. Algo puede ser fundamental en un sentido sin serlo en el otro. De un modo general, si $x$ está fundado en $y$, entonces $[\square((y$ existe $) \rightarrow(x$ existe $))]$. Al contrario, si $x$ depende ontológicamente de $y$, entonces $[\square((x$ existe $) \rightarrow(y$ existe $))]$. Por ejemplo, el estado de cosas de instanciar $x$ el universal $U$ en el tiempo $t$ depende ontológicamente de $U$, de $x$ y de $t$, pero no está fundado en $U, x$ y $t$. El estado de cosas, en efecto, no puede existir sin sus constituyentes, pero la existencia de sus constituyentes no garantiza la existencia del estado de cosas. Un estado de cosas es fundamental, entonces, en el sentido (b), pero no en el sentido (a). Una estatua constituida de un pedazo de bronce con cierta configuración puede estar fundada en el pedazo de bronce que la constituye, pero no ser dependiente de este pedazo, pues podría estar constituida por otro material. Es algo fundamental en el sentido (a), pero no en el sentido (b). Aquí se toma 'fundamental' en el sentido (a).

25 Es más, se ha sostenido que la posibilidad metafísica de una existencia desligada del cuerpo para una persona implica que las personas son sustancias no corpóreas (Swinburne, 1984, pp. 22-26). En efecto, por la necesidad de la identidad se sigue, por contraposición, que $[(\diamond(x \neq y) \rightarrow(x \neq y))]$. 
sustancia dotada de propiedades mentales -los estados mentales en que se encuentre- no se pretende sostener que su identidad en el tiempo esté determinada por el carácter intrínseco de tales estados mentales, tal como sucede en la teoría psicológica. Una misma persona podría perder la memoria de sus estados mentales anteriores y esto no tendría ninguna relevancia para su identidad en el tiempo. En casos en que, por ejemplo, se hace un trasplante de los dos hemisferios cerebrales del señor Pérez en el cuerpo de dos personas diferentes, sean González y Rojas, no habrá, probablemente, ninguna forma de determinar si es que Pérez es idéntico o no a alguna de las personas resultantes de los trasplantes, si es que lo es. Todo lo que podríamos afirmar es que es un hecho determinado que el señor Pérez o bien es idéntico a uno y solo uno de entre González o Rojas después del trasplante, o bien no lo es. El que no tengamos criterios para verificar epistemológicamente esta cuestión no impide que exista un hecho determinado -y primitivo- de identidad o diferencia. Supóngase ahora que el telencéfalo del señor Pérez es trasplantado al señor González. El cuerpo del señor Pérez sigue funcionando de manera vegetativa porque se preserva ahí su diencéfalo. De acuerdo a una concepción dualista, es un hecho determinado que o bien el señor Pérez seguirá existiendo en el cuerpo de González o bien no. No tenemos criterios epistemológicos suficientes para decidir esta cuestión, pero esto no obsta a que exista un hecho determinado de identidad o diferencia. Aunque uno aquí podría pensar más verosímil desde una perspectiva dualista que Pérez debería ser idéntico a la persona en el cuerpo de González - pues parece tener los mismos estados mentales- no es esto algo respecto de lo que no hay evidencia suficiente.

Es una consecuencia de la teoría 'animalista' en donde las personas son entendidas como organismos biológicos que en todo instante en que exista el organismo, existirá también la persona. Cada uno de nosotros, entonces, ha sido alguna vez un feto y, si uno llega a sufrir en el futuro un accidente grave, podríamos llegar a quedar en estado vegetativo, sin conciencia alguna. En un dualismo tal como el que se ha presentado, sin embargo, no puede sostenerse justificadamente ninguna de estas tesis. La relación que tenga la persona con un cuerpo es tal como la

Sea la persona $a$ y sea el cuerpo que le está asociado $b$. Si es posible metafísicamente que $a$ exista sin un cuerpo, entonces $[\diamond(a \neq b)]$, de lo que se sigue que $[(a \neq b)]$. Por supuesto, ningún filósofo no dualista aceptaría que es posible metafísicamente una persona sin cuerpo, lo que no impide que uno pueda concebir ese escenario. 
relación que uno pudiera tener con una herramienta. Una persona utiliza un cuerpo tal como uno ocupa un automóvil -la imagen tradicional es la de un piloto en una nave. Uno puede suponer justificadamente que el organismo desarrollado de un ser humano adulto y consciente es algo que debemos respetar, pues dañando ese organismo dañamos a la persona que lo utiliza, pero no tenemos elementos de juicio suficientes para sostener que un feto está ya de algún modo siendo utilizado por alguna persona. Hay justificación para pensar que un organismo está siendo utilizado por una persona si es que ese organismo muestra una conducta apropia$\mathrm{da}$, usa correctamente un lenguaje y muestra capacidades conceptuales superiores. Nada de esto, sin embargo, podemos observar en un feto o en un niño pequeño. Tampoco lo podemos observar en un organismo humano en estado vegetativo. No se trata de que tengamos aquí evidencia de que no son personas o de que se trata de organismos no utilizados por personas. Se trata simplemente de que no hay evidencia suficiente para suponer una cosa o la otra. Si las personas deben ser tratadas de un modo especial -tal como se ha hecho notar más arriba- el animalismo obliga a tratar de este modo a fetos y enfermos en estado vegetativo. El dualismo, en cambio, no obliga directamente a sacar estas conclusiones ${ }^{26}$.

Pero este dualismo no es la única alternativa abierta en este caso. Uno puede sostener también una concepción no-cartesiana en donde las personas son sustancias, con condiciones de identidad primitivas (Lowe, 1996, pp. 14-51). Se puede tratar de sustancias que poseen una naturaleza apropiada para llegar a desarrollar conciencia y capacidades cognitivas superiores. A diferencia del dualismo cartesiano, sin embargo, se puede suponer que estas sustancias no solo poseen propiedades mentales, sino también propiedades físicas. Los defensores de una posición como esta sostienen que no hay motivos para que una sustancia con estados mentales no pueda tener también propiedades físicas, ni para suponer que una sustancia con propiedades físicas no tenga propiedades mentales. Uno puede admitir que no hay ninguna propiedad mental determinada, ni ninguna propiedad física determinada que sea poseída esencialmente por las personas, pero sí es esencial para ellas tener alguna propiedad mental y alguna propiedad física,

26 De un modo indirecto, la situación en el caso de una teoría dualista podría ser similar a lo que sucede en el animalismo. Si hay ignorancia respecto de si un curso de acción va a dañar a una persona, entonces uno debe abstenerse de seguirlo. 
dentro de ciertos márgenes de admisibilidad. ¿Qué sucede en una concepción de este tipo frente a los supuestos tradicionales que han generado problemas para diferentes teorías de la identidad personal? No puede identificarse aquí a una persona con un organismo biológico, pero tampoco puede suponerse que el organismo sea una mera herramienta utilizada por la persona. La relación viene a ser bastante más sutil. El 'organismo' que asociamos con una persona debería designar un evento del que la persona es un agente. Se trata de la secuencia de propiedades físicas poseídas por la persona en el tiempo, y por la secuencia de operaciones realizadas por ella como agente. Ninguna persona puede, por lo tanto, ser identificada con un organismo biológico, pero también resulta que ninguna persona -humana, al menos- podría desplegar su actividad y desarrollar su naturaleza -al menos espacialmente- sin que esto resulte en un organismo biológico. Su actividad en el tiempo es, en efecto, la asimilación de nutrientes, la combustión metabólica de algunos de estos, la constitución de estructuras celulares, la coordinación de pluralidades de células para conformar órganos y tejidos, entre otras cosas. La cuestión es que no se trata de que una sustancia inmaterial llegue a utilizar un cuerpo humano que estuviese ya constituido. Lo que denominamos un 'cuerpo humano' existe por la acción de la sustancia en que consiste la persona. El cuerpo humano es el despliegue espacial de las operaciones de la persona.

Resulta en una teoría de este tipo, por lo tanto, que las intuiciones fundamentales acerca de los casos de trasplante de cerebro, o de hemisferios cerebrales son semejantes a las del animalismo. No puede haber algo así como un organismo biológico de un ser humano sin que exista una persona del que ese organismo es la acción. No puede separarse la persona en una secuencia de estados psicológicos que transmigre de organismo en organismo. Los casos de pérdida masiva de memoria y otros cambios bruscos en el carácter cualitativo de los estados mentales no pueden generar un cambio de persona, o su desaparición. Aunque el príncipe recuerde todas las experiencias del zapatero, y el zapatero recuerde todas las experiencias del príncipe, el príncipe sigue siendo el príncipe, y el zapatero sigue siendo el zapatero. Existe aquí, sin embargo, un espacio más amplio para ciertos supuestos que en el 'animalismo' son menos aceptables. Resulta difícil de admitir, por ejemplo, que un corazón artificial pueda llegar a ser parte de un organismo biológico desde una perspectiva animalista. Un corazón artificial es un artefacto, no es un tejido orgánico. Desde la perspectiva de quien defienda una concepción de la 
persona como una sustancia primitiva, cuál sea el origen de algo en lo que se despliega la acción espacial de tal sustancia no tiene relevancia. Alguien podría llegar a tener un cuerpo completamente artificial mediante sustituciones paulatinas de diferentes órganos en el tiempo. Para un animalista, el resultado final ya no sería un organismo biológico y, por lo tanto, ya no sería una persona. Para un defensor de la tesis de que las personas son sustancias primitivas, se trataría del cuerpo de la misma persona que antes vivía con tejidos de células.

\section{Conclusiones}

SE HAN PRESENTADO AQUí ALGUNOS MOTIVOS para rechazar las teorías psicológicas de la identidad personal y las teorías en donde esta es tratada por 'partes temporales' o 'supervivientes temporales'. Solo entidades que pueden persistir en el tiempo endurando parecen satisfacer nuestras intuiciones normativas acerca de las personas -esto es, que es moralmente incorrecto matarlas, dañarlas física o psíquicamente, etcétera. Si lo que entendemos como 'personas' son meramente fusiones mereológicas de personas instantáneas, o meramente secuencias de personas instantáneas que pueden ser caracterizadas como 'supervivientes' unas respecto de las otras, es muy difícil hacer inteligibles tales intuiciones. Una concepción adecuada de la 'persona' debe respetar, por lo menos, este requerimiento teórico: las personas deben ser entidades que, por su naturaleza, deben poder endurar en el tiempo.

Un tipo de teoría de gran prevalencia en buena parte del siglo pasado ha intentado explicar reductivamente las condiciones de identidad de las personas a la continuidad psicológica entre sus estados mentales. La experiencia de varios decenios de discusión filosófica es que la teoría psicológica es completamente inadecuada. Aún con todas las sofisticaciones propuestas, la continuidad psicológica no parece ni suficiente ni necesaria para la identidad personal. Se oponen a la suficiencia los casos en que dos personas diferentes entre sí llegan a tener continuidad psicológicamente con una tercera, con la que deberían ser idénticas si la teoría psicológica fuese correcta. Se oponen a la necesidad los casos en los que una misma persona -o lo que parece ser obviamente la misma persona- deja de tener continuidad psicológica entre dos instantes de tiempo. 
Si la teoría psicológica debe ser rechazada, las alternativas que quedan abiertas son dos: el animalismo o alguna concepción de las personas como sustancias primitivas. Por supuesto, uno también podría aquí sostener alguna concepción nihilista donde sencillamente no hay personas. Mantener, por ejemplo, que todo lo que hay son etapas personales instantáneas que conforman fusiones mereológicas o que se encuentran entre sí en relaciones de 'supervivencia' serían concepciones de este tipo. En la teoría animalista las personas son organismos biológicos y sus condiciones de identidad son las condiciones de identidad de un organismo. Las teorías en las que las personas son sustancias primitivas, con condiciones de identidad también primitivas, incluyen alternativas dualistas tradicionales, pero también concepciones en donde la persona es la que, por su agencia, genera un organismo humano. En estas últimas alternativas no puede disociarse a la persona de un organismo humano, sin que sea necesario identificar a la persona con tal organismo. Hay costos y beneficios teóricos para todas estas diferentes teorías no psicológicas de la identidad personal. La adjudicación de cuál de ellas sea preferible es una cuestión abierta que requerirá un examen ulterior mucho más detallado que el que ha podido hacerse aquí ${ }^{27}$.

\section{Apéndice. Problemas modales para la teoría psicológica}

LA TEORÍA PSICOLÓgICA SE HA PRESENTADo como una teoría acerca de las condiciones de identidad en el tiempo de las personas. No se ha pensado que las condiciones de identidad temporal deberían ser también apropiadas para las condiciones de identidad entre diferentes mundos posibles. Pero esto no parece razonable. Si las personas son esencialmente una secuencia de estados psicológicos con cierto carácter intrínseco, si cuál sea el cuerpo en donde se realicen tales estados psicológicos o en los que estén fundados tales estados psicológicos es

27 Este trabajo ha sido redactado en ejecución del proyecto de investigación Fondecyt 1120015 (Conicyt, Chile). Versiones preliminares han sido presentadas en el Workshop Ontología de la persona (26 de junio de 2014), en el Seminario Cuestiones acerca del cuidado de la vida (11 de agosto de 2014), en las X Jornadas Internacionales de Derecho Natural (19 al 22 de agosto de 2014), en el seminario del Centro de Bioética (21 de agosto de 2014) y en las XV Jornadas Libertad, Responsabilidad, Sexualidad (29 de octubre de 2014). Agradezco a los comentarios y sugerencias de los asistentes en esos encuentros. Agradezco también los múltiples comentarios de Alejandra Carrasco y Olof Page a las ideas presentadas aquí. 
irrelevante para la identidad de una persona -recuérdese que una persona podría subsistir un cambio de cuerpo- no se ve por qué esto no debería tener relevancia para la cuestión modal. De acuerdo con el principio de Continuidad psicológica, si el señor Pérez amanece con todos los estados psicológicos del señor González, y el señor González amanece con todos los estados psicológicos del señor Pérez, entonces la persona en el cuerpo de Pérez es González, y la persona en el cuerpo de González es Pérez. Pues bien, esto también debería valer para las condiciones de identidad de una persona entre diferentes mundos posibles. Un mundo posible con alguien con los mismos rasgos físicos que el señor González pero que posee exactamente los mismos estados mentales que el señor Pérez, es un mundo posible en donde existe el señor Pérez y no el señor González. La persona en un cuerpo como el de González en ese mundo posible es idéntica al señor Pérez y no al señor González.

Tal como para el caso temporal, se producen aquí casos de fisión modal y de fusión modal de personas. Supóngase que el señor Pérez en $w_{1}$ tiene un estado mental total $m$. Este estado mental 'total' debe suponerse como la fusión de todos los estados mentales de Pérez en todos los instantes de tiempo en que Pérez existe en $w_{1}$. En el mundo posible $w_{2}$ hay dos personas, los señores González y Rojas, que poseen por igual el estado mental total $m^{28}$. Esta hipótesis parece perfectamente posible. De acuerdo con el principio de Continuidad psicológica, debería suceder que Pérez-en- $w_{1}=$ González-en- $w_{2}$, y debería suceder que Pérez-en- $w_{1}=$ Rojas-en- $w_{2}$. Se sigue que González-en- $w_{2}=$ Rojas-en- $w_{2}$, pero es obvio que se trata de personas diferentes. Supóngase ahora que en el mundo $w_{1}$ hay dos personas diferentes, los señores Pérez y González, que poseen estados psicológicos totales extremadamente semejantes, sean $m_{1}$ y $m_{2}$, respectivamente, pero distintos en, al menos, el hecho de que Pérez cree que hace frío en el tiempo

28 Se requerirían aquí algunas prevenciones. Lo que debe contar para el estado mental total es el aspecto 'cualitativo' de tales estados mentales. No deben contar los pensamientos de se de González y Rojas. Si, por ejemplo, González piensa que él mismo tiene un dolor de cabeza, este pensamiento será diferente del pensamiento de Rojas de que él mismo tiene un dolor de cabeza. En estos casos es el pensador un integrante del contenido pensado y, por lo tanto, González estará pensando de González (de re) que tiene un dolor de cabeza y no de Rojas (de re) que tiene un dolor de cabeza, y viceversa para Rojas. Algo semejante debería suponerse para pensamientos con contenido 'singular' -tal como pensar que eso es una mesa, en donde eso hace referencia a una mesa particular en el ambiente del pensador y con la que tenga alguna familiaridad perceptiva. 
$t$, mientras que González no cree que hace frío en $t$. Puede suponerse que $t$ es un lapso de tiempo tan pequeño como se quiera. Todo lo demás es idéntico entre los estados mentales totales $m_{1}$ y $m_{2}$. En el mundo posible $w_{2}$ solo hay una persona, el señor Rojas, que tiene un estado mental total idéntico cualitativamente a $m_{1}$. Es obvio que Rojas-en- $w_{2}=$ Pérez-en- $w_{1}$, pues tienen exactamente el mismo estado mental total $m_{1}$. Sucede, sin embargo, que también Rojas-en- $w_{2}=$ Gonzálezen- $w_{1}$, pues los estados mentales totales $m_{1}$ y $m_{2}$ cuentan como 'continuos' entre sí de acuerdo con la teoría psicológica. De hecho se exige muchísimo menos semejanza para la identidad temporal. No hay ninguna otra persona con la que pueda ser identificado González en $w_{2}$. Dos personas diferentes vienen a ser posiblemente la misma persona. Esto implica que las dos personas que son posiblemente idénticas deberían ser actualmente idénticas. Recuérdese que la identidad es necesaria. Pero esto es absurdo.

Lo anterior es una réplica de los problemas clásicos de la teoría psicológica como teoría de la identidad personal inter-temporal para el caso modal. Existen aquí, sin embargo, problemas específicos mayores. La continuidad psicológica entre dos etapas personales no es identidad de los estados psicológicos de dos etapas personales. Solo se exige que exista suficiente semejanza en creencias, preferencias, intenciones y rasgos de carácter, junto con la memoria de los estados mentales de las etapas personales anteriores. Para el caso modal no se puede exigir, por supuesto, algo así como 'memoria' de las experiencias en otros mundos posibles. Si se aplica esta idea para las identidades personales entre diferentes mundos posibles, el resultado es desastroso. Supóngase que el señor Pérez en $w_{1}$ posee un estado mental total $m_{1}$. En el mundo posible $w_{n}$, el señor González posee un estado mental total $m_{n}$ extremadamente diferente de $m_{1}$. Puede suponerse, por ejemplo, que Pérez es un egipcio de la primera dinastía, mientras que González es un astronauta del siglo XXV. No importa lo diferente que puedan ser Pérez y González, existe una secuencia de identidades personales entre diferentes mundos posibles que conecta a Pérez y González. Cualquiera sea la cualidad intrínseca del estado mental total $m_{1}$, hay un estado mental total $m_{2}$ que puede diferir mínimamente respecto de $m_{1}$ y que asemeja -aunque sea un pocoel estado mental total de Pérez al estado mental total de González. Cualquiera sea la cualidad intrínseca del estado mental total $m_{2}$, hay un estado mental total $m_{3}$ que puede diferir mínimamente del estado mental total $m_{2}$ y que asemeja otro 
poco el estado mental total de Pérez al estado mental total de González, y así sucesivamente. Si se reitera este procedimiento todas las $n$ veces que sea necesario, va a resultar que el estado mental total de Pérez en el mundo posible $w_{\mathrm{n}-1}$ será psicológicamente continuo con el estado mental total de González en el mundo posible $w_{\mathrm{n}}$. De acuerdo con el principio de Continuidad psicológica, Pérez-en- $w_{\mathrm{n}-1}$ $=$ González-en- $w_{\mathrm{n}}$. Lo mismo sucede para cada uno de los $n$ pasos de la secuencia que conecta a Pérez-en- $w_{1}$ con González-en- $w_{\mathrm{n}}$. Por tanto, sucede que -de acuerdo con la teoría psicológica- Pérez-en- $w_{1}=$ González-en- $w_{\mathrm{n}}$, pues la identidad es transitiva. No solo es esto contra-intuitivo, sino que este resultado no es simplemente una infeliz circunstancia que afecta a los señores Pérez y González. Puede ser generalizado para dos personas cualesquiera. No importa lo disímiles que sean. No importa que vivan en culturas radicalmente diferentes. Cualquier persona debería ser posiblemente idéntica con cualquier otra. Dado que la identidad es necesaria, se sigue que toda persona sería actualmente idéntica con cualquier otra. Sería una consecuencia de la teoría psicológica, por lo tanto, que solo habría una única persona. Y esto sería un hecho necesario.

Si uno tuviese algún reparo con los problemas temporales de la teoría psicológica de la identidad personal, los problemas que presenta esta teoría desde el punto de vista modal son mucho mayores. Las teorías psicológicas deben, por lo tanto, ser rechazadas.

Referencias

Armstrong, D.M. (1978). A Theory of Universals. Universals and Scientific Realism. Vol. II. Cambridge: Cambridge University Press.

Baker, L.R. (2000). Persons and Bodies. A Constitution View. Cambridge: Cambridge University Press.

Descartes, R. (1979). Méditations Métaphysiques. Objections et réponses suivies de quattre lettres. Paris: Flammarion.

Haslanger, S. (2003). Persistence through Time. M.J. Loux \& D.W. Zimmerman (Eds.), The Oxford Handbook of Metaphysics (pp. 315-354). Oxford: Oxford University Press.

Heller, M. (1990). The Ontology of Physical Objects. Four-Dimensional Hunks of Matter. Cambridge: Cambridge University Press. 
Johnston, M. (1999). Human Beings. J. Kim \& E. Sosa (Eds.), Metaphysics. An Anthology (pp, 393-407). Oxford: Blackwell.

Lewis, D. (1986). On the Plurality of Worlds. Oxford: Blackwell.

Lewis, D. (1991). Parts of Classes. Oxford: Blackwell.

Locke, J. (1975). An Essay Concerning Human Understanding. P.H. Nidditch (Ed.). Oxford: Clarendon Press.

Lowe, E.J. (1996). Subjects of Experience. Cambridge: Cambridge University Press.

Nagel, T. (1971). Brain Bisection and the Unity of Consciousness. J. Perry (Ed.), Personal Identity (pp. 227-245). Berkeley: University of California Press.

Noonan, H.W. (2003). Personal Identity. London: Routledge.

Olson, E.T. (1997). The Human Animal. Personal Identity without Psychology. New York: Oxford University Press.

Olson, E.T. (2003). An Argument for Animalism. Raymond, M. \& Barresi, J. (Eds.), Personal Identity (pp. 318-334). Oxford: Blackwell.

Olson, E.T. (2007). What Are We? A Study in Personal Ontology. Oxford: Oxford University Press.

Olson, E.T. (2010). Personal Identity. Ed. Zalta (Ed.), Stanford Encyclopedia of Philosophy, http://plato.stanford.edu/entries/identity-personal. Recuperado: 11.11.14.

Parfit, D. (1971). Personal Identity. J. Perry (Ed.), Personal Identity (pp. 199-223). Berkeley: University of California Press.

Parfit, D. (1984). Reasons and Persons. Oxford: Clarendon Press.

Perry, J. (ed.) (2008). Personal Identity. Berkeley: University of California Press. Raymond, M. \& Barresi, J. (Eds.). (2003a). Personal Identity. Oxford: Blackwell. Raymond, M. \& Barresi, J. (2003b). Introduction. Personal Identity (pp. 1-74). Oxford: Blackwell.

Shoemaker, S. (1970). Persons and their Pasts. J. Perry (Ed.), Personal Identity (pp. 249-282). Berkeley: University of California Press.

Shoemaker, S. (1984). Personal Identity. A Materialist's Account. S. Shoemaker $\&$ R. Swinburne (Ed.), Personal Identity (pp. 67-132). Oxford: Blackwell. Snowdon, P.F. (2014). Persons, Animals, Ourselves. Oxford: Oxford University Press. 
Swinburne, R. (1984). Personal Identity. The Dualist Theory. S. Shoemaker \& R. Swinburne (Ed.), Personal Identity (pp. 1-66). Oxford: Blackwell. van Inwagen, P. (1990). Material Beings. Ithaca: Cornell University Press. Wiggins, D. (2001). Sameness and Substance Renewed. Cambridge: Cambridge University Press.

Williams, B. (2003). The Self and the Future. Raymond, M. \& Barresi, J. (Eds.), Personal Identity (pp. 75-91). Oxford: Blackwell. 